\title{
ELECTROLYTIC DECONTAMINATION OF METAL LOW LEVEL WASTE (LLW) AND MIXED LOW LEVEL WASTE (MLLW).
}

\section{PROJECT REPORT.}

\section{SUMMARY}

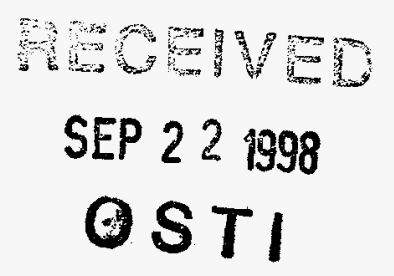

Metal objects resulting from ER activities were decontaminated using electrolytic methods. The project involved about $500 \mathrm{~kg}$ of ballistic test projectiles, 23 augers and drill heads, and 50 pieces of shrapnel containing lead. All objects were free-released and either reclaimed as scrap metal or reused. Electrolytic decontamination was proven to be an effective method to decontaminate metal waste objects to free-release standards. A cost analysis showed the process to be economical, especially when applied to decontamination of mixed waste, TRU waste, or when the recovered materials could be reused or recycled. The cost of decontamination of scrap iron is approximately equal to the cost of its land disposal as low level waste.

\section{BACKGROUND}

Metal projectiles and shrapnel pieces contaminated with uranium were uncovered during the ER activity at LANL TA-33. The projectiles were used in tests which dated back to 1940-ties. There were 38 pieces of projectiles and 50 pieces of shrapnel varying in size. The total weight of the metal waste was about 0.5 metric ton. The projectiles were placed in three 55-gallon drums. These projectiles could be disposed of as low level waste (LLW). The shrapnel pieces, packed in one 55 gallon drum, were made of an alloy containing lead, and were considered Mixed Low Level Waste (MLLW). The MLLW could not be disposed at LANL. According to the Resource Conservation and Recovery Act (RCRA) regulations MLLW has to be treated and buried at a site licensed to accept such waste. Presently, Envirocare a company in Utah, offers treatment and disposal services for such waste.

A decision was made to test the electrolytic decontamination process that could decontaminate these wastes. Such treatment would result in free-release of the material and in avoiding the disposal of radioactive waste. Such approach would benefit the environment and could establish a cost effective method for future ER activities. A RCRA Treatability Study exemption had to obtained in order to process the MLLW shrapnel.

Steel augers and drill-heads, used for sampling soils at several feet depth were also chosen for treatment by this technology. The augers had fixed contamination with Sr90. After the decontamination they were reused instead of being disposed of as LLW.

J Dziewinski, S. Marczak, J. Anderson, J. Murphy, CST-7
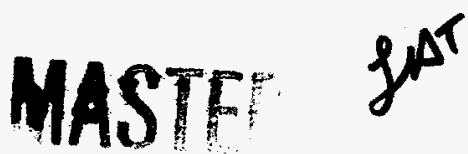

Electrolytic decontamination of metal low level waste (llw) and mixed low level waste (milw). 


\section{DISCLAIMER}

This report was prepared as an account of work sponsored by an agency of the United States Government. Neither the United States Government nor any agency thereof, nor any of their employees, makes any warranty, express or implied, or assumes any legal liability or responsibility for the accuracy, completeness, or usefulness of any information, apparatus, product, or process disclosed, or represents that its use would not infringe privately owned rights. Reference herein to any specific commercial product, process, or service by trade name, trademark, manufacturer, or otherwise does not necessarily constitute or imply its endorsement, recommendation, or favoring by the United States Government or any agency thereof. The views and opinions of authors expressed herein do not necessarily state or reflect those of the United States Government or any agency thereof. 


\section{DISCLAIMER}

Portions of this document may be illegible in electronic image products. Images are produced from the best available original document. 


\section{DECONTAMINATION OF PROJECTILES CONTAMINATED WITH URANIUM}

\subsection{Treatment:}

\subsubsection{Drum opening.}

The drums containing the projectiles were transported to the Radioactive Materials Management Area at TA-48, building RC-1, room 423 and opened inside a walk-in hood. They were surveyed for fixed and removable radioactivity using Eberline TA55HF $\alpha$ and $\beta+\gamma$ portable monitors.

\subsection{Decontamination.}

\subsubsection{A. Washing with $0.2 \mathrm{M}$ citric acid.}

All projectiles were very badly corroded. There was no possibility to establish an electrical contact with metallic surface of the projectiles. It was decided to wash the projectiles overnight with citric acid prior to electrochemical decontamination. This procedure removed part of soil and some loose rust from the surface and partially exposed bare metal.

\subsubsection{B. Cathodic decontamination.}

In this process a contaminated projectile served as a cathode and a titanium grid covered with $\mathrm{TiO}_{2}$ and a mixture of noble metals as an anode. $0.1 \mathrm{M} \mathrm{H}_{2} \mathrm{SO}_{4}$ was used as an electrolyte. Current flow (up to $100 \mathrm{~mA} / \mathrm{cm}^{2}$ ) causes a reduction of surface layer of iron oxides and hydrogen evolution. Reduction of the surface oxides lowers an adhesion of thick crust of the rust to the projectile. At the same time hydrogen bubbles strip pieces of rust off the projectile's surface. During the cathodic decontamination the composition of electrolyte does not change. After filtering of soil and pieces of rust the electrolyte can be reused.

\subsubsection{Anodic decontamination.}

During the anodic decontamination each projectile was connected to a positive pole of a rectifier. Carbon steel grid was connected to a negative pole and served as a cathode. $0.1 \mathrm{M} \mathrm{H}_{2} \mathrm{SO}_{4}$ was used as an electrolyte. Current flow (about $100 \mathrm{~mA} / \mathrm{cm}^{2}$ ) caused dissolution of the thin surface layer of the projectile. Depending on the contamination level various electrolysis times were used. The shortest time of electrolysis ( 2 hours) resulted in stripping of $0.025 \mathrm{~mm}$ thick layer from the surface. In three cases the electric current up to $400 \mathrm{~mA} / \mathrm{cm}^{2}$ was used and electrolyses were conducted for $\mathbf{4 8}$ hours. These allowed to dissolve $2.4 \mathrm{~mm}$ thick layers from projectiles' surface.

Surface radioactivity was measured after each step of the decontamination.

Electrolytic decontamination of metal low level waste (llw) and mixed low level waste (mllw). 
The chemical composition of solutions from each step of decontamination was determined using ICP-AES. In each case RCRA elements concentrations were below the Radioactive Wastewater Treatment Plant disposal limits.

\subsection{Results.}

Some results are presented below as illustrative examples. The projectiles used in these examples were named: "with screw"; "16"; "nail"; "middle"; "large"; and "drill". Their initial radioactivities varied.

Generally all projectiles could be divided into four groups: a) projectiles decontaminated with citric acid, b) projectiles which needed all three steps of decontamination, $c$ ) projectiles on which some additional radioactive sources were exposed after citric acid wash, d) projectiles with volume contamination.

The first three are represented in the graphs below. The projectiles described as "with screw" and "\#16" belong to group a); "nail" and "middle" to group b) and "large" and "drill" - to group c). It is interesting to note that the $\beta+\gamma$ measurements went up after the citric wash in case of "large" and "drill". Some radioactive sources were uncovered.

Only 3 projectiles belonged to group d). All three of them had an upper part badly damaged and initially covered with yellow cake. Initial radioactivity readings showed up to $75,000 \mathrm{cpm} \beta+\gamma$ and $5000 \mathrm{cpm} \alpha$ (measured with Eberline TA55HF monitors). Washing in citric acid removed the yellow cake from the tops of the projectiles but it did not result in contamination decrease. Both, cathodic and anodic decontaminations failed to lower the contamination on these three projectiles. A 2.2 $\mathrm{mm}$ thick layer of projectiles' surface was removed before further efforts were abandoned. It was concluded that these projectiles were volume rather than surface contaminated. 

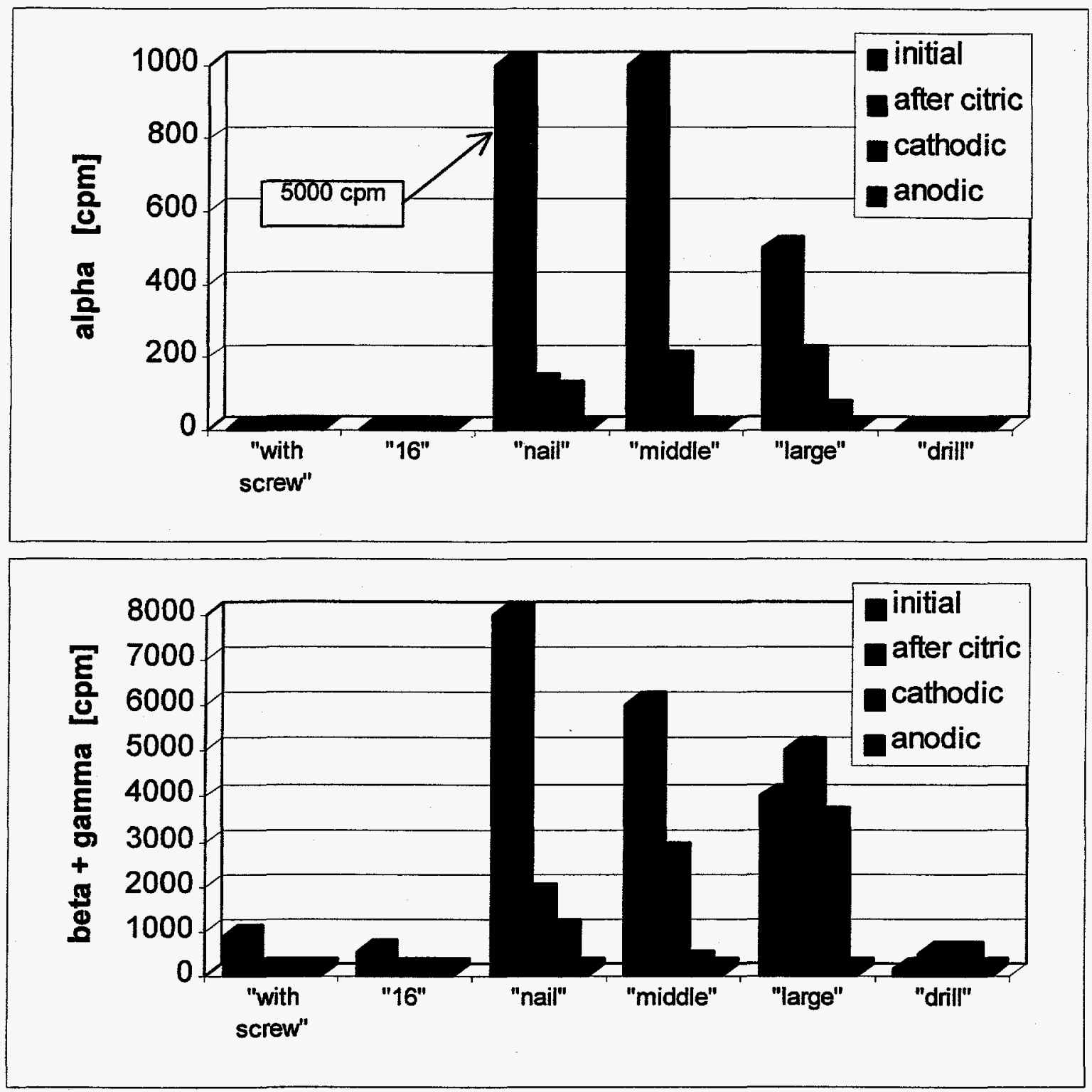

Figure 1. Projectile decontamination.

\subsubsection{Summary.}

38 projectiles weighing approximately $500 \mathrm{KG}$ were received for electrolytic decontamination. 35 of them were decontaminated to background level, met free release criteria and were approved by ESH-1 for free-release. Laboratory Procedure (LP)10704.1 "Releasing Materials and Equipment" implements the requirements of DOE order 5400.5 and is more stringent than the DOE order. Three projectiles showed volume contamination and could notbe released. 


\section{AUGERS AND DRILL HEADS}

\subsection{Treatment}

A total of 3 drill heads and 20 augers were received and treated. According to the accompanying information these objects were contaminated with $\mathrm{Sr} 90$ and the contamination was fixed (not smearable). Each object was carefully checked with $\alpha$ and $\beta+\gamma$ monitors (Eberline SRM 100) before and after each treatment step. Alpha contamination was not found on neither the received augers or drill heads. The contamination with $\beta+\gamma$ emitters was a spot - type and activity varied from $400 \mathrm{cpm}$ to over $2000 \mathrm{cpm}$.

The augers and drill heads were subjected to a two step decontamination. The first step consisted of overnight washing in $0.2 \mathrm{M}-0.5 \mathrm{M} \mathrm{H}_{2} \mathrm{SO}_{4}$. Higher acid concentration was used when a treated auger was more contaminated. Washing bath had a volume of $100 \mathrm{~L}$. During the overnight washing a surface layer of the auger was dissolved and the acid concentration dropped to below $10^{-3} \mathrm{M}$. In the morning the washed auger was removed and rinsed with tap water and a new auger was placed in the bath. An appropiate amount of $96 \%$ sulfuric acid was added to reach $\mathrm{H}_{2} \mathrm{SO}_{4}$ concentration between $0.2-0.5 \mathrm{M}$ and a new auger was left in the bath till the next day. No stirring was used. One volume of the bath was used to wash 10 augers.

An ICP-AES analysis found $500 \mathrm{ppm}$ of chromium and about $13 \mathrm{~g} / \mathrm{L}$ of iron in the final solution. This solution was neutralized to $\mathrm{pH}$ between 6 and 7 in order to precipitate chromium and iron hydroxides. After settling down a dense cake of the hydroxides was separated and the clear solution was analyzed again. Only $0.5 \mathrm{ppm}$ of chromium was found in this solution. No other RCRA elements were present and the solution could be disposed to the sink which drains to the TA-50 Radioactive Wastewater Treatment Plant (RWTP). The cake was filtered under vacuum and dried. The filtrate was disposed of to the drain (no RCRA elements were found in the clear filtrate). Solid hydroxides (a mixture of $\mathrm{Fe}(\mathrm{II}), \mathrm{Fe}$ (III) and Cr(III) hydroxides) passed the TCLP test and were disposed of as a low-level waste.

When after the first step of decontamination the augers or drill heads still remained radioactive they were submitted to a second step. This step consisted of electrolytic removal of a metal surface layer. An auger (or a drill head) served as an anode and a carbon steel grid was used as a cathode. $100 \mathrm{~L}$ of $0.1 \mathrm{M} \mathrm{H}_{3} \mathrm{PO}_{4}$ was used as an electrolyte. The augers were electrolyzed for 16 hours with $30 \mathrm{~A}$ current. The voltage did not exceed $4 \mathrm{~V}$. After the electrolysis the augers were rinsed with tap water, let to dry and the radioactivity was measured. After the separation of a small amount of solid (iron phosphate), the electrolyte solution was analyzed by ICP-AES. No RCRA components were found so solution could be disposed to the drain.

\subsection{Results:}

20 augers and 3 drill heads were decontaminated to the background level, free released and reused by the ER project 
About $15 \mathrm{~kg}$ of chromium and iron hydroxides and $200 \mathrm{~g}$ of iron phosphate were disposed of as low level waste. $2 \mathrm{~kg}$ of soil was collected from the bottom of the tank. This soil passed TCLP and was disposed to laboratory trash box.

\section{SHRAPNEL}

\subsection{Treatment.}

One drum containing 50 shrapnel pieces of various sizes and compositions was received. The drum was opened under a walk-in hood and up to 10 pieces were removed at the time. $\alpha$ and $\beta+\gamma$ radioactivity was measured and the pieces were placed in $1 \mathrm{M}$ acetic acid solution. The solution was stirred overnight. Next morning the pieces were removed, rinsed with a small amount of water and dried. The brass pieces were separated from steel and aluminum shrapnel pieces.

After measuring the radioactivity the brass shrapnel were placed in $1 \mathrm{M}$ $\mathrm{CH}_{3} \mathrm{COOH}$ solution and electrolyzed. Shrapnel served as anodes while stainless steel beakers or aluminum foils were used as cathodes. Voltage was kept below $4 \mathrm{~V}$, current depended on dimensions of a shrapnel. For the smallest pieces $0.1 \mathrm{~A}$ was used, for the largest ones the current was equal to $3 \mathrm{~A}$. The time of electrolysis depended on contamination level. Less contaminated pieces were electrolyzed for 8 hours, more contaminated ones up to 20 hours. One acetic acid solution was used for electrolysis of up to 10 shrapnel.

During the electrolysis a surface layer of shrapnel was dissolved and the contamination was removed. On cathodes some metal powder was deposited at the same time. This powder was removed and the electrolyte solution was filtered before reuse. The metal powder consisted of copper, lead and cadmium and it did not pass the TCLP test ( $8.3 \mathrm{ppm}$ of $\mathrm{Pb}, 1.0 \mathrm{ppm}$ of Cd in the TCLP test).

5 shrapnel pieces consisted of separable smaller parts. These pieces were disassembled and each part was monitored for contamination and treated separately. (in two cases a contamination was found on surfaces disclosed after the disassembly). Small non-metallic parts from the disassembly were rinsed with diluted nitric acid. Rinse solution contained no RCRA elements. This solution was disposed of to the RWTP and the non-metallic parts to the laboratory trash boxes.

6 brass shrapnel were badly damaged with a deep cracks and some holes. They required electrolysis for up to 20 hours. Some radioactive dark spots from holes were removed by rinsing them with $1-2 \mathrm{~mL}$ of $30 \% \mathrm{HNO}_{3}$.

Aluminum and steel shrapnel, and steel screws from shrapnel disassembly were first washed in $0.2 \mathrm{M} \mathrm{HCl}$. After acid wash the radioactivity of aluminum pieces and screws was reduced to the background level. The ICP-AES analysis showed no presence of RCRA elements and the solution was disposed of to the RWTP. Two steel pieces were still radioactive (one up to $400 \mathrm{cpm} \beta+\gamma$, second up to $700 \mathrm{cpm} \beta+\gamma$; no $\alpha$ ). They were electrolyzed the same way as brass shrapnel.

Electrolytic decontamination of metal low level waste (llw) and mixed low level waste (mllw). 


\subsection{Results:}

Examples of treatment results are presented on the graphs below. All shrapnel shown on the graphs were made of brass.

Each step of treatment removed some decontamination. Washing in acetic acid removed some loose dirt and part of contamination. After this step it was easy to find electric contact with shrapnel surface. Anodic decontamination lowered the radioactivity to a background level and brass shrapnels recovered their gold-like look.

All the received shrapnel were decontaminated from radioactivity to meet the free release criteria.
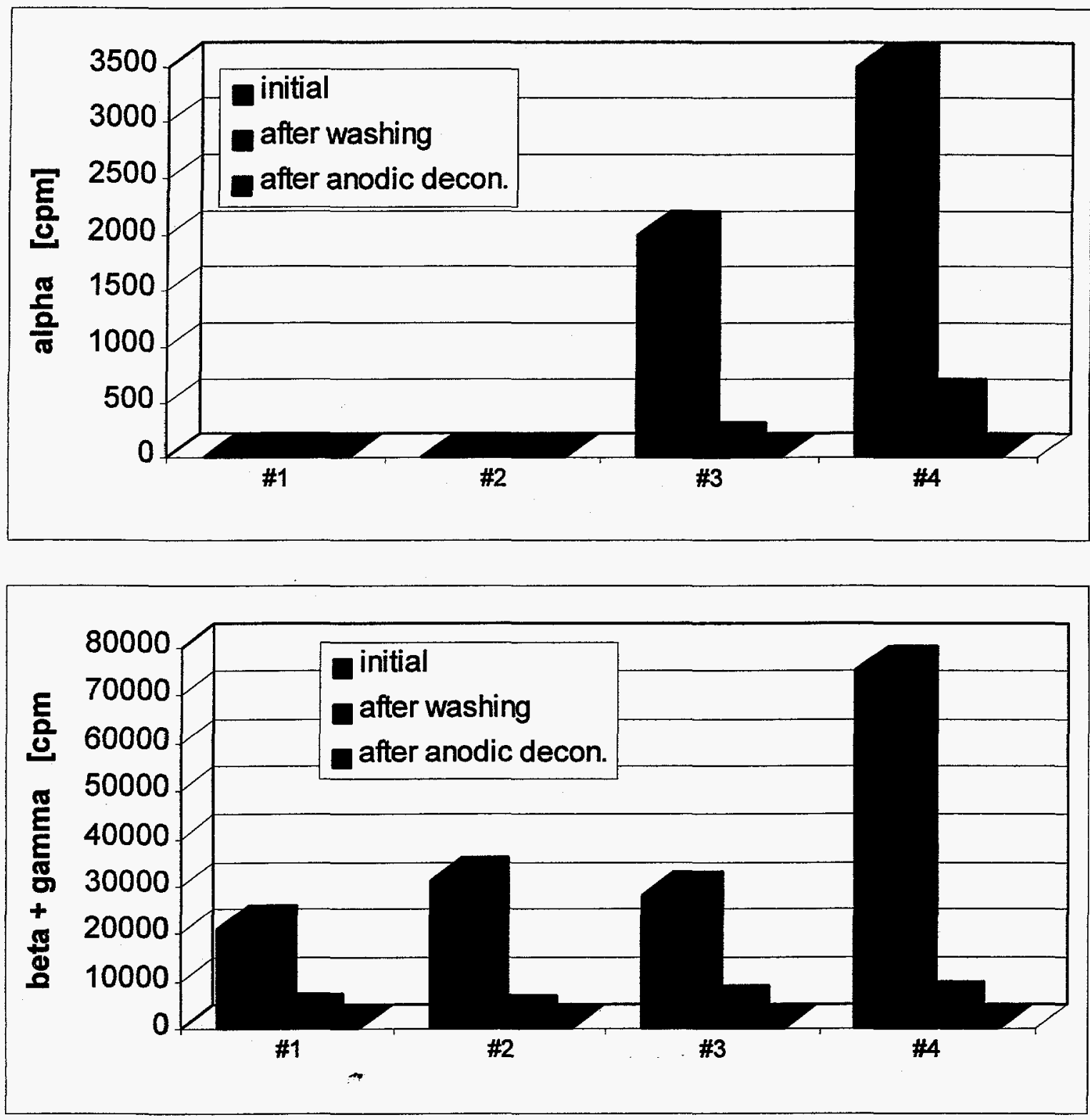

Fig 2. Decontamination of shrapnel.

J Dziewinski, S. Marczak, J. Anderson, J. Murphy, CST-7

Electrolytic decontamination of metal low level waste (llw) and mixed low level waste (mllw). 
Shrapnel decontamination operations produced total $10 \mathrm{~L}$ of acetate solution containing $\mathrm{Cu}, \mathrm{Pb}$ and $\mathrm{Cd}$. About $100 \mathrm{ml}$ of nitrate solution with $\mathrm{Cu}, \mathrm{Pb}$ and $\mathrm{Cd}$ was mixed together. Lead was separated from solution as a $\mathrm{PbHPO}_{4}$. This solid passed TCLP test and was disposed as a LLW. Next cadmium was separated by $\mathrm{Cd}(\mathrm{OH})_{2}$ precipitation with ammonia. Finally $\mathrm{Cd}(\mathrm{OH})_{2}$ was transformed into insoluble salt with $\mathrm{Na}_{2} \mathrm{~S}$. This salt passed TCLP test and was disposed as LLW. Treated solution contained no RCRA components and was disposed off to RETP.

\section{CONCLUSIONS}

Electrolytic decontamination was proven to be an effective method to decontaminate metal waste objects to free-release standards. The total cost of this developmental project was $\$ 28,500$. These costs, over and above the operating costs, included capital costs necessary to perform the operations, and the costs of obtaining a RCRA treatability study exemption for MLLW.

Had this project not been pursued the costs of disposal of the treated items using established methods would have been as follows:

projectiles (LLW) - characterization and disposal at LANL, about $\$ 1,000$;

shrapnel (MLLW) - characterization, transportation, treatment and disposal at Envirocare, about $\$ 10,000$;

augers and drill-heads - characterization and disposal as LLW, about $\$ 5,000$;

- purchase of new items, about $\$ 11,500$;

Hence, the total expenses for using conventional means would have been $\$ 27,500$, nearly the same as the expenditures of this developmental project. One may say that a new technology was tested, improved, and implemented at practically no cost to the taxpayer. At the same time two young scientists could be employed and gain valuable experience at LANL for two months.

A cost evaluation for the Electrolytic Processing was performed by TSA-4 [1]. This evaluation was possible because of carrying out this developmental project. The cost evaluation shows that electrolytic processing of waste, when implemented at a routine (not developmental) basis, has a clear and significant economical advantage when applied to MLLW and TRU waste. It also results in substantial cost savings for LLW when waste items can be recovered and recycled. For the case of LLW which does not represent any reclaimed material value, the electrolytic processing applied at a small scale presently shows no economic benefits over land burial. The benefits for this case may however lie in ethical grounds by greatly minimizing land disposal of radioactive waste.

\section{CITATION}

[1] "Cost Effectiveness of Electrolytic Processing for LANL Radioactive Wastes", Mark Cummings, Los Alamos National Laboratory, TSA-4, Energy and Environmental Analysis Group. October 1997. 


\section{ACKNOWLEDGMENT.}

We appreciate the support of Roy Michelotti and Beverly Martin of CST-7 without whom this project could not have been accomplished. We wish to acknowledge the dedication of Mark Cummings who performed the cost analysis. 